\title{
AC 2008-446: AN INTEGRATIVE APPROACH TO UNDERGRADUATE AND GRADUATE CHANGE
}

\section{Tom Eppes, University of Hartford}

Tom A. Eppes is an Associate Professor of Electrical and Computer Engineering in the College of Engineering, Technology, and Architecture at the University of Hartford. He holds Bachelor and Master of Science degrees in Electrical Engineering from Texas A\&M University and a Ph.D. in Electrical Engineering from the University of Michigan.

\section{Ivana Milanovic, University of Hartford}

Ivana M. Milanovic is an Associate Professor of Mechanical Engineering in the College of Engineering, Technology, and Architecture at the University of Hartford. She received her Ph.D. in Mechanical Engineering from Polytechnic University, NY and M.S. and B.S. from University of Belgrade in Yugoslavia.

\section{Janice Girouard, University of Hartford}

Janice Girouard is the Director of Student Services for the College of Engineering, Technology, and Architecture at the University of Hartford. She earned her BFA at the Hartford Art School, University of Hartford and her M.Ed. at the College of Education, Nursing and Health Professions, University of Hartford. 


\title{
An Integrative Approach to Undergraduate and Graduate Change
}

\begin{abstract}
This paper describes the efforts we undertook when faced with several strategic challenges and opportunities in strengthening our graduate and undergraduate programs. First, a Flex Advantage Plan (FAP) was developed to enhance our undergraduate engineering technology (ET) programs by better utilizing the inherent curricular flexibilities that were laying dormant. FAP provides distinction and uniqueness to program majors by presenting students with educational choices that add depth in a chosen discipline and/or another area of study.

A proposal to enhance our graduate program was subsequently prepared. A new Masters of Industrial Management (MIM) would be introduced as an interdisciplinary course-based program with a curriculum that spans three realms of study: technical, management and special topics. MIM is envisioned to complement the current project-based Masters program and enable its transition to a thesis-based track.

The need to improve the linkage between our undergraduate and graduate studies is also discussed. We intend to expand eligibility and increase awareness for undergraduate students as well as create more relevant alternatives for part-time graduate students. Such an integrated approach is expected to yield a sequence of enrollment increments as the proposed changes are implemented and publicized within our target market. This in turn should set the stage for the migration to a thesis-based Masters. The changes we have made or proposed create an array of educational pathways greater than the sum of their parts.
\end{abstract}

\section{Introduction and Strategic Setting}

The University of Hartford is predominantly an in-residence undergraduate institution. However, graduate programs are present in most of the University's colleges and represent approximately one-fourth of all students. We are members of the College of Engineering, Technology, and Architecture (CETA) that has a population of about 900 students of which 100 are enrolled in a Master's program. Graduate enrollment in CETA is $11 \%$ of total students which is below the University average. In addition, specializations are offered in Civil, Environmental, Electrical and Mechanical Engineering which further dilutes the student body and CETA's resources.

The University is conveniently located among a vibrant array of high technology companies. Full-time enrollment comes mostly in the form of international students. We speculate that our part-time enrollment is under-developed since the current Master's program is a single track project-based curriculum. This approach does not appeal to students desiring to perform a thesis nor those who prefer a course-based track.

Our projected recruiting environment is complicated by two emerging factors. First, students are increasingly aware of the need to broaden their skill base upon graduation and recognize the need to compete for employment on a global scale. Secondly, an in-state public high school drop in graduates of $9.4 \%$ is forecasted from 2008-16. ${ }^{1}$ This downward trend is mirrored on a national scale in which similar declines are predicted with no reversal until $2016 .^{2}$ In addition, a higher 
percentage of high school graduates will come from families with low incomes. ${ }^{3}$ To meet these challenges, a response at both the undergraduate and graduate levels is required. We began by developing the Flex Advantage Plan (FAP) to enhance our engineering technology (ET) programs and in hope that it would complement ensuing efforts on the graduate side. ${ }^{4}$

\section{Undergraduate Engineering Technology Response}

Our undergraduate response, i.e. FAP, precisely targets opportunities for complementary areas of study and encourages students to design custom educational plans. Until recently, the systematic use of electives in the academic advising process was done by self-motivated faculty and students. To create a more consistent and sustainable approach, we established the goal of identifying specific tracks within the ET curricula so as to add educational value with minimal credit overload. Flexible curricula designed along these lines deliver a richer experience that enables graduates to expand their skills and equip themselves for a broader array of career choices.

FAP provides distinction and uniqueness to program majors by presenting students with educational choices that add depth in a chosen discipline and/or another area of study. FAP is also integrated into the CETA's marketing collateral, open house recruiting events and orientation sessions to engage and retain first-year students. FAP is successfully being used to stimulate student interest, increase participation, and thus improve their prospects for lifelong career success.

Table 1 shows the FAP matrix for all ET programs, both current and future. There are three possible tracks in each program: Business Advantage, Arts \& Communication and Technical Depth. The Business Advantage track, the most established, spans all programs and offers up to five minors. Arts \& Communication is popular with Architecture and Audio majors since it resonates with the artistic interests of these students. Technical Depth affords the largest number of choices with a multi-disciplinary array of associate degrees, minors and concentrations.

FAP is an evolving process whereby new options are consistently being incorporated. Over the last year, two technical minors were added. Currently, we are developing one technical minor and a concentration.

To assist faculty and staff with implementation and tracking, advising worksheets were created. These worksheets identify the courses required, both within and outside the curriculum, to complete a specific option. Table 2 illustrates how tabs are used to enable more convenient access to major-specific options. Each tabbed worksheet employs color coding to highlight specific course pre-requisites and requirements. 
Table 1 - Specific FAP curriculum options for each ET program

\begin{tabular}{|c|c|c|c|}
\hline \multicolumn{4}{|c|}{ Technology Program Matrix } \\
\hline Program & Business Advantage & Arts \& Communication & Technical Depth \\
\hline MET & $\begin{array}{ll}- & \text { Business Admin } \\
\text { - } & \text { Management } \\
\text { - } & \text { Entrepreneurship } \\
\text { - } & \text { Marketing } \\
\end{array}$ & & $\begin{array}{ll} & \text { AS EET } \\
- & \text { AuET minor } \\
- & \text { CET minor } \\
\circ & \text { EET minor } \\
\circ & \text { Photonics } \\
\circ & \text { Mechatronics } \\
\end{array}$ \\
\hline EET & $\begin{array}{ll}- & \text { Business Admin } \\
\text { - } & \text { Management Information } \\
& \text { Systems } \\
\text { - } & \text { Entrepreneurship } \\
\text { - } & \text { Management } \\
\text { - } & \text { Marketing }\end{array}$ & & $\begin{array}{ll}- & \text { AS CET } \\
- & \text { MET minor } \\
- & \text { AuET minor } \\
- & \text { CET minor }\end{array}$ \\
\hline CET & $\begin{array}{ll}\text { - } & \text { Business Admin } \\
\text { - } & \text { Management Information } \\
& \text { Systems } \\
\text { - } & \text { Entrepreneurship } \\
\text { - } & \text { Management } \\
\text { - } & \text { Marketing }\end{array}$ & & $\begin{array}{ll}- & \text { AS EET } \\
\text { - } & \text { Computer Science } \\
& \text { minor } \\
\text { - } & \text { Networking } \\
\circ & \text { Mechatronics }\end{array}$ \\
\hline AuET & $\begin{array}{ll}- & \text { Business Admin } \\
\text { - } & \text { Management } \\
\text { - } & \text { Marketing } \\
\text { - } & \text { Entrepreneurship } \\
\end{array}$ & $\begin{array}{ll}\text { - } & \text { Communication } \\
\text { - } & \text { Cinema/Film }\end{array}$ & $\begin{array}{ll}- & \text { AS EET } \\
- & \text { AS CET } \\
- & \text { MET minor } \\
- & \text { CET minor } \\
\circ & \text { EET minor } \\
\end{array}$ \\
\hline AET & $\begin{array}{ll}\text { - } & \text { Business Admin } \\
\text { - } & \text { Marketing } \\
\text { - } & \text { Management }\end{array}$ & $\begin{array}{ll}\text { - } & \text { Fine Arts } \\
\text { - } & \text { Art History }\end{array}$ & - MET minor \\
\hline \multicolumn{4}{|c|}{$\begin{array}{l}\text { Legend: } \\
\text { - Currently in place } \\
\text { - Future offering }\end{array}$} \\
\hline
\end{tabular}


Table 2 - Sample worksheet for MET - Business Admin minor

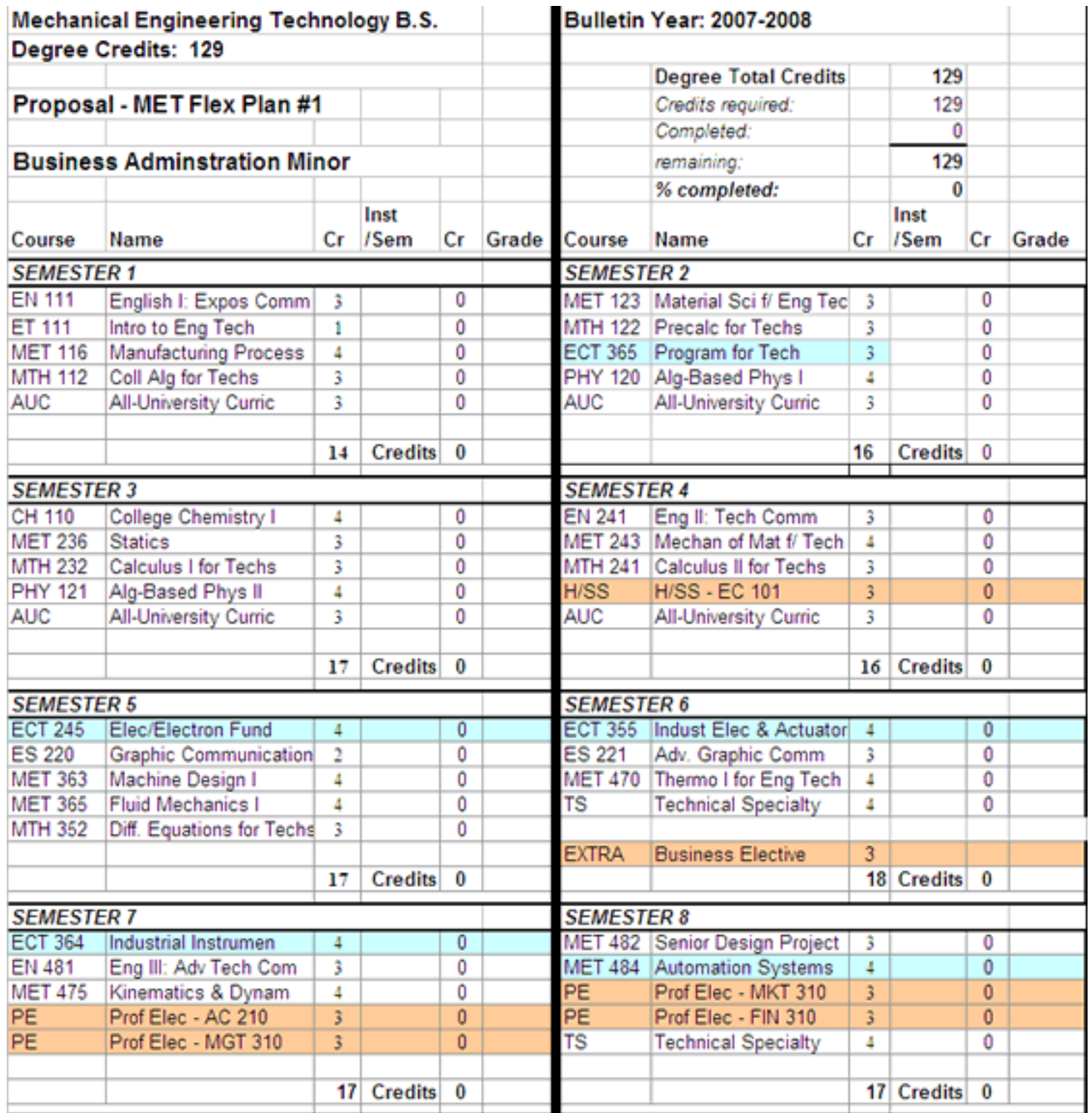

\section{Total Credits $129 \mathrm{c}$ plus Bus Elec $=132$}

Acceptable

\section{Business Adminstration Minor}

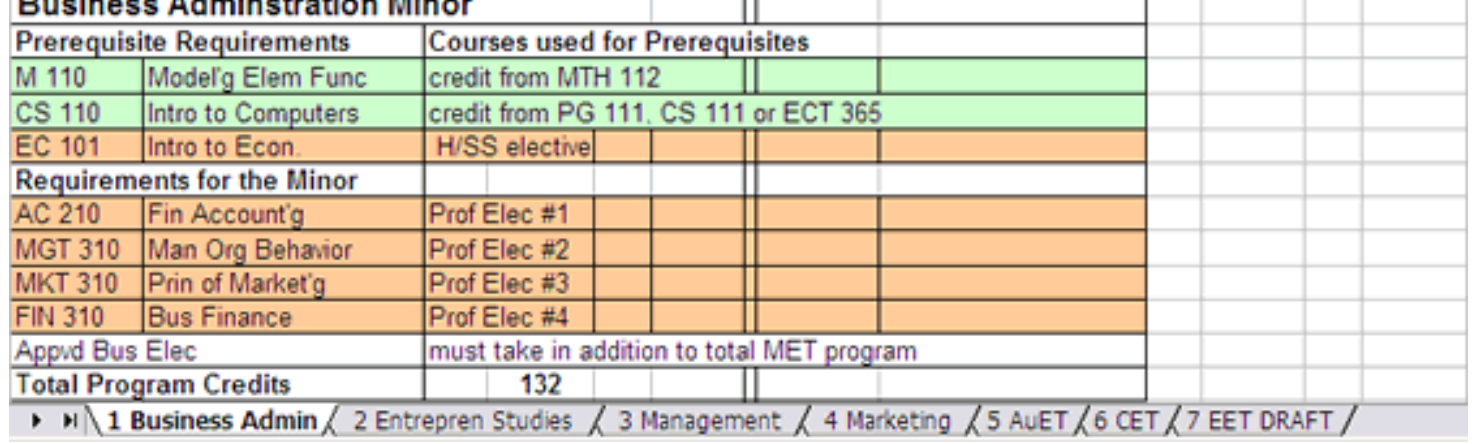




\section{Graduate Program Response}

The next step was to focus attention on the graduate program. The strategic setting led us to reexamine the under-served constituencies within our target market:

- All of our graduates (both engineering and technology) need pathways for continuing education within the CETA

- Many practicing professionals prefer a broader curriculum, e.g. interdisciplinary or management

- Movement toward a strong thesis-bases master's option is desirable

Recall that out of 900 students, 100 or $11 \%$ are enrolled in the Master's program with a flat trend over multiple years. Graduate students are spread across seven specializations sponsored by four different departments. Graduate advising and teaching is handled by a fraction of the 34 full-time faculty which limits the number of students that can be supported in the current 6-9 credit research course sequence (project-based not thesis-based). Singularly and collectively, the above factors have limited growth within the program.

A number of concerns emerged in recent years indicating a need for fundamental change within the graduate program. These concerns are:

- Low average course enrollment

- Too many technical concentrations

- Not enough full-time faculty

- Student/local industry needs not fully served

The impact of globalization has led to a major thrust on the part of all industries to increase the performance of their industrial and business systems. The underlying production and delivery processes needed to undergo transformation in design and management so that consistent product and service quality are maintained. Continuous change is forcing organizations and people in industrialized countries to make a qualitative transition. In global companies, this transformation is almost completed; however, in academic education organizations, it is still at its infancy. ${ }^{5}$ Our current Masters program was/is not configured to address this challenge.

We developed a plan to re-structure the current Masters program (project-based). In our proposal, re-structuring would occur in two stages. In Stage 1, a new course-based program, Masters of Industrial Management (MIM), would be introduced in response to the regional industrial sector we serve. MIM would be an interdisciplinary program with a curriculum drawn from the course banks of two entities, CETA and the Barney School of Business.

A minimum of 30 credit hours of course work would be required. Teaching assistantships (TAs) would not be offered for students on this track. The curriculum would span three realms of coursework: technical, management and special topics. The technical set would be drawn from a six existing courses some of which are 500-level that can be taken by senior undergraduates for dual credit. The management courses would be taken from a six existing courses, again some of which are 500-level courses. Special topic courses would round out the course list and emphasize 
emerging technologies and globalization. This area is expected to be highly dynamic and change with the pace of leading-edge innovation in industry.

MIM will have broad appeal and draw students from a number of backgrounds and industrial sectors:

- Managers/supervisors from local industry wishing to pursue a Masters degree other than an MBA

- Practicing engineers who want/need to develop expertise in the management process to further their careers

- Technology graduates across multiple disciplines who want to further their formal education

- Engineering graduates across multiple disciplines who want to prepare for a career in engineering management

- Science disciplines (e.g. Physics, Chemistry, Biology)

MIM is anticipated to be accretive to the overall graduate program with solid enrollment demand from the outset. CETA will benefit during Stage 1 since overall graduate enrollment and the number of students in some current courses will rise. MIM will also expand our network of students and industrial partners. Stage 1 will have a positive impact on the bottom line economic performance of the graduate program.

It has long been thought that the distinctiveness of the current project-based program could be enhanced if it were changed to a thesis track. Hence, Stage 2 will focus on the migration of the current project-based Masters program to a thesis track. Stage 2 will be fueled by the financial improvement brought about in Stage 1 since the thesis track will require additional full-time faculty as well as tuition waivers for selected full-time students.

It should be noted that fewer than desired undergraduates initiate their graduate studies immediately. So, in spite of a high affinity for CETA and an awareness of the graduate program, a small number of students elect to take graduate-level courses during their senior year. We believe that improved undergraduate participation could be achieved by actively promoting 500level courses and introducing special topic courses that address emerging technologies, globalization and sustainability.

\section{Integration of Graduate \& Undergraduate Programs}

CETA adopted a "3+2" initiative several years ago whereby an engineering senior could take up to two courses that would count for both undergraduate and graduate degrees. We would like to see more qualified students availing themselves of this offering. We believe that the proposed restructuring will energize our Masters program with more undergraduate students immediately transitioning into graduate study.

Adoption by our student constituency was critical to the success of both FAP, and we expect the same for MIM. Consequently, implementation must be done in a comprehensive manner by leveraging every available opportunity and resource to trigger active participation. A host of 
internal processes and targeted events have been identified as key opportunities to stimulate awareness, communicate benefits and drive enrollment.

\section{CREATE AWARENESS}

- Industry Partners - The support and buy-in from our industry partners are essential to the long term success of both Masters tracks. This is best accomplished by collaborating with our contacts at both the technical and managerial levels across a full range of venues.

- Marketing Collateral - CETA publishes and distributes program-oriented brochures throughout the academic year. Most are mailed to prospective students or handed out at open house events. CETA and department web pages will also include FAP and graduate program content.

- Open House Events - A number of graduate and undergraduate open houses are held each academic year. These events are ideal opportunities to discuss the merits of specific programs, particularly those that have been added or enhanced.

\section{ENGAGE CURRENT STUDENTS IN CREATING EDUCATIONAL ROAD MAP}

- $1^{\text {st }}$ Year Orientation - For ET students, the emphasis will remain on FAP; however, the idea of lifelong learning and transition into MIM would be introduced. For engineering students, summary information on both Masters tracks would be provided.

- $1^{\text {st }}$ Year Dialog Course - Each first-year student is required to register for a one-credit freshmen dialog course. ET students learn the importance of course planning and the details of the FAP educational road map. Interested students carefully select a sequence of course electives that complement other required courses by the major. Engineering students are given more in depth information on the Masters programs and listen to speakers describe emerging skills needed in the workforce.

\section{STUDENT ADVISING}

- Undergraduate Academic Advising - This is a key opportunity to present and discuss educational plans and follow up on how students are progressing both within their major as well as with other pathways they have elected to pursue. Promising $3^{\text {rd }}$ year students are encouraged to take 500-level courses as a bridge into the graduate program.

\section{Conclusions}

Faced with several strategic challenges and opportunities, we undertook initiatives both at the undergraduate and graduate level. FAP successfully enhanced our ET programs by taking advantage of the inherent curricular flexibilities that were largely dormant. FAP provides distinction and uniqueness to program majors by presenting students with educational choices that add depth in a chosen discipline and/or another area of study. 
We have also developed a plan to re-structure our graduate program, which currently is exclusively a project-based Master of Engineering. In our proposal, MIM would be introduced as an interdisciplinary program with a curriculum that spans three realms of coursework: technical, management and special topics. Subsequently, we will focus on the migration of the current project-based Masters program to a thesis track.

As a final step, our plan addresses the need to improve the linkage between our undergraduate and graduate studies. The aim is to create a smoother transition for current undergraduate students and relevant alternatives for part-time students. Given such an integrated approach, we expect to see a sequence of enrollment increments as the proposed changes are implemented and publicized within our target market. Following the introduction of FAP, we experienced enrollment increases, and we expect this to be the same with MIM. This in turn will help drive overall enrollment and set the stage for migration to a thesis-based Masters. The overall benefits of the improvement discussed in this paper will create an array of educational pathways that are greater than the sum of the parts.

\section{References}

1. The Board of Governors for Higher Education, Department of Higher Education, State of Connecticut, Report, November 2007.

2. Western Interstate Commission for Higher Education (WICHE), "Knocking at the College Door: Projections of High School Graduates by State, Income, and Race/Ethnicity," December 2003.

3. The College Board, "The Impact of Demographic Changes on Higher Education," Summary of Conference Discussions, July 27-28, 2005, Philadelphia, Pennsylvania.

4. Girouard, J., Milanovic, I. M., Eppes, A. T., "Creating Flexible and Distinct Engineering Technology Programs," 2007 ASEE Annual Conference Proceedings, Honolulu, Paper ASEE-2007-81.

5. Lehto, S., "Transforming Engineering Education from the Maintaining Mode of Operation to the Development Mode of the Global Industry," 2002, URL: http://www.iacee.org/newsletters/sefi-lehto.pdf. 